\title{
Use of the cross-leg distally based sural artery flap for the reconstruction of complex lower extremity defects
}

\author{
Weihao Liang, Bien Keem Tan \\ Department of Plastic, Reconstructive and Aesthetic Surgery, Singapore General Hospital, Singapore
}

Cross-leg flaps are a useful reconstructive option for complex lower limb defects when free flaps cannot be performed owing to vessel damage. We describe the use of the extended distally based sural artery flap in a cross-leg fashion for lower extremity coverage in three patients. To maximise the viability of these extended flaps, a delay was performed by raising them in a bipedicled fashion before gradual division of the tip over 5 to 7 days for cross-leg transfer. Rigid coupling of the lower limbs with external fixators was critical in preventing flap avulsion and to promote neovascular takeover. The pedicle was gradually divided over the ensuing 7 to 14 days before full flap inset and removal of the external fixators. In all three patients, the flaps survived with no complications and successful coverage of the critical defect was achieved. One patient developed a grade 2 pressure injury on his heel that resolved with conservative dressings. The donor sites and external fixator pin wounds healed well, with no functional morbidity. The cross-leg extended distally based sural artery flap is a reliable reconstructive option in challenging scenarios. Adequate flap delay, manoeuvres to reduce congestion, and postoperative rigid immobilization are key to a successful outcome.

Keywords Leg injuries / Sural nerve / Perforator flap / Surgical flaps / External fixators
Correspondence: Bien Keem Tan Department of Plastic, Reconstructive and Aesthetic Surgery, Singapore General Hospital, Academia, 20 College Road, Singapore 169856, Singapore

Tel: $+65-6321-4686$

Fax: $+65-6227-3573$

E-mail: bienkeem@gmail.com

Received: 18 May 2017 - Revised: 2 Sep 2017 • Accepted: 24 Oct 2017

pISSN: 2234-6163 • elSSN: 2234-6171 • https://doi.org/10.5999/aps.2017.00892 • Arch Plast Surg 2019;46:255-261

\section{INTRODUCTION}

Today, microsurgical free flaps are the gold standard for lower limb reconstruction, with success rates approaching $95 \%$. Crossleg flaps have largely been relegated to history, but it would be remiss of any reconstructive surgeon committed to limb salvage to forget this age-old technique. The indications for a cross-leg flap include the salvage of a single vessel limb, severely traumatized extremities with poor recipient veins, and polytrauma precluding long surgery $[1,2]$.

Traditionally, cross-leg flaps have employed a broad-based ran- dom pattern design that limits the reach and requires prolonged immobilization for neovascular take-over. The purpose of this paper is to describe the use of the extended distally based sural artery flap in a cross-leg fashion. The benefits of this flap include a long reach, a wide arc of rotation, minimal donor site morbidity, and avoidance of sacrificing a major artery $[3,4]$.

\section{CASES}

From July 2002 to October 2016, a total of three patients sustained lower extremity defects that were not amenable to local 
or free flap reconstruction due to severe vascular compromise secondary to trauma. The cross-leg extended distally based sural artery flap was used to reconstruct their defects. The patients' profile, defect location and dimensions, and postoperative outcomes are presented in Table 1.

The surgical technique for the harvest of a distally based sural artery flap has been well described [5-8]. Preoperatively, the lateral leg perforators are marked with a handheld Doppler. These are usually located 5 to $8 \mathrm{~cm}$ above the lateral malleolus and in the posterior crural septum. These perforators largely emanate from the peroneal artery and occasionally from the posterior tibial artery system, and their position determines the pivot point $[9,10]$. The flap axis is marked by drawing a line joining the perforator marking to the centre of the popliteal crease. The flap design is elliptical to encompass the short saphenous vein and the sural nerves (lateral and medial sural nerves, apart from the common sural nerve). The base measures $1.5 \mathrm{~cm}$ and is left broad to facilitate venous drainage; we do not island the flap for the same reason. To determine the adequacy of flap reach, the legs are brought together and flap transposition is simulated with a template.

We commence the elevation of the flap proximally, identifying the sural nerve, short saphenous vein, and the superficial sural artery, all of which are included in the flap. An additional $5 \mathrm{~cm}$ of the short saphenous vein is mobilized as a venous pedicle, which is divided, exteriorized, and temporarily occluded with a microvascular clamp (TKMV-1; Synovus, Birmingham, AL, USA) [11]. Dissection is then carried out distally to the marked location of the peroneal perforators. Proximally, the sural nerve pierces the deep fascia and is located in the groove between the medial and lateral heads of the gastrocnemius muscle. The deep fascia is incised, and dissection in this groove is performed to locate the subfascial course of the sural nerve. The sural nerve, together with the adipofascial tissue connecting the nerve to the deep fascia, is included with the flap.

The sural nerve courses distally until the midpoint of the leg, where it emerges from underneath the deep fascia. From this point, the sural nerve and the short saphenous vein are located suprafascially, and dissection can proceed expediently. As the distal leg perforators are approached, care should be taken to ensure inclusion of the short saphenous vein, which diverges from the sural nerve and runs medially toward the Achilles tendon. The surgeon can check its course by tracing the vein through the translucent deep fascia.

Venous congestion is assessed about 30 minutes after raising the flap. Venous congestion is determined clinically by the flap's colour and rapidity of capillary refill. If congestion is present, the short saphenous vein is released for blood to drain [11]. If congestion is not observed after 30 minutes, the short saphenous vein is occluded with a microvascular clamp, which can be released as needed. This is done in case the flap develops congestion in the ward as the flap warms up.

In a cross-leg situation, to make the tip more robust (since survival depends on it developing collateral circulation), flap delay is routinely performed. In the first stage of surgery, the flap is completely raised as a bipedicled flap and the wound bed beneath the flap skin is grafted. The flap tip is then gradually divided over 7 days in 5-mm increments. In the second stage of surgery, the flap is inset to the defect, and both lower extremities are rigidly coupled together with an external fixator construct. Delay is also performed for the flap base by dividing it by $5 \mathrm{~mm} /$ day so that with adequate training, the entire flap can be "waltzed" over to the defect during the third and final stage of surgery. If less skin is needed, a portion of the redundant flap can be returned to the donor site.

The cross-leg period ranges from 3 to 4 weeks. To reduce secondary infection, the flap could be partially tubed or skin grafted over its underbelly. Attention is paid to maximizing contact with the wound bed throughout the entire period to facilitate neovascularization. Supplementary sutures may be placed if loosening occurs. Rigid immobilization using external fixators is crucial for this process, and only removed upon complete division

Table 1. Patients' profiles, defect details, and outcomes

\begin{tabular}{|c|c|c|c|c|c|c|c|c|}
\hline $\begin{array}{l}\text { Patient } \\
\text { no. }\end{array}$ & $\begin{array}{l}\text { Age } \\
(y r)\end{array}$ & Sex & Comorbidities & Indications & Wound characteristics & Site of defect & $\begin{array}{l}\text { Size of critical } \\
\text { defect }(\mathrm{cm})\end{array}$ & Complications \\
\hline 1 & 60 & Female & Hypertension & $\begin{array}{l}\text { Single-vessel leg, } \\
\text { inadequate veins }\end{array}$ & $\begin{array}{l}\text { Severe equinus deformity from posterior } \\
\text { ankle scarring. Previous open tibia-fibula } \\
\text { fracture with extensive degloving. }\end{array}$ & Posterior ankle & $8 \times 9$ & None \\
\hline 2 & 31 & Male & None & $\begin{array}{l}\text { Skin defect over } \\
\text { below-knee } \\
\text { amputation stump }\end{array}$ & $\begin{array}{l}\text { Multi-level crush injury of the leg. Leg was } \\
\text { not viable. }\end{array}$ & $\begin{array}{l}\text { Below-knee } \\
\text { amputation } \\
\text { stump }\end{array}$ & $16 \times 6$ & None \\
\hline 3 & 20 & Male & None & $\begin{array}{l}\text { Single-vessel leg with } \\
\text { extensive degloving } \\
\text { and lack of veins }\end{array}$ & $\begin{array}{l}\text { Crush injury with open tibia/fibula fracture, } \\
\text { complicated by osteomyelitis. }\end{array}$ & Distal leg & $6 \times 10$ & $\begin{array}{l}\text { Heel pressure } \\
\text { injury (grade 2) } \\
\text { of recipient leg }\end{array}$ \\
\hline
\end{tabular}


and inset of the flap.

In all three patients, the cross-leg extended distally based sural artery flap survived with no tissue loss. Successful coverage of the critical defects was achieved in all three patients. There were no cases of surgical wound infection, haematoma, seroma, or external fixator pin-site complications. There was no venous congestion with intermittent phlebotomy of the short saphenous vein.

One patient (case 3 ) developed a grade 2 pressure injury on the heel of the recipient leg due to the weight of the external fixator construct. The heel ulcer healed with conservative dressings after division of the flap and removal of the external fixator construct. The other two patients did not develop complications related to prolonged bed-rest and immobilization. All three patients reported fully healed donor sites with no functional morbidity.

\section{Case 1}

A 60-year-old woman had a motor vehicle accident 5-year prior to her current presentation. Her injuries included segmental open fractures of the left tibia and fibula, extensive soft tissue degloving, and vascular injuries. The posterior tibial artery was the sole vessel supplying the foot. Soft tissue reconstruction was achieved with a free latissimus dorsi muscle flap anastomosed in an end-to-side fashion to the posterior tibial artery. Progressive scarring over her Achilles tendon and neglect had resulted in a fixed equinus deformity of the ankle (Fig. 1A). Her gait was severely hampered as a result, and she had to walk with a tip-toe using a walking frame.
Corrective surgery involved complete release of the Achilles tendon and fusion of the ankle joint in a neutral position. The resultant $8 \times 9 \mathrm{~cm}$ posterior ankle defect exposed the posterior tibial artery, which was found to be patent but severely scarred, and the decision was made not to use it as a recipient vessel for free tissue transfer. A cross-leg distally based sural artery flap was raised to cover the defect (Fig. 1B). Her legs were immobilized with external fixators, with both hips externally rotated to approximate the flap and defect. Staged, incremental division of the pedicle was performed over 2 weeks to ensure flap survival. With correction of the equinus deformity and successful soft tissue coverage, she was able to walk independently of walking aids after 6 months of physical therapy.

\section{Case 2}

A 30-year-old man sustained a severe crush injury to the right leg in a motor vehicle accident. Owing to the multi-level crush injury, a below-knee amputation was performed. The amputation stump was left partially open due to skin deficiency (Fig. $2 \mathrm{~A})$. In this instance, shortening the stump would have allowed wound closure, but a foreshortened stump would have reduced the stability of his future prosthesis. Obtaining suitable recipient vessels for a free flap transfer would have entailed vein grafts traversing the knee joint to reach the adductor canal. Weighing the risks against the benefits of a free flap, the patient elected for a pedicled flap option. A cross-leg distally based sural artery flap with an extended design was used after a delay procedure. The flap was tubed and its tip initially inset over the medial aspect of the amputation stump. After 2 weeks, his hips were maximally

\section{Fig. 1. A case of heel defect}

This 60-year-old woman had a previous extensive degloving injury of the left leg and had undergone reconstruction with a free latissimus dorsi flap. (A) Neglect and scarring over the Achilles tendon led to an equinus deformity. (B) After tendon release and ankle arthrodesis, the posterior tibial neurovascular bundle was exposed. The defect was covered with the flap.
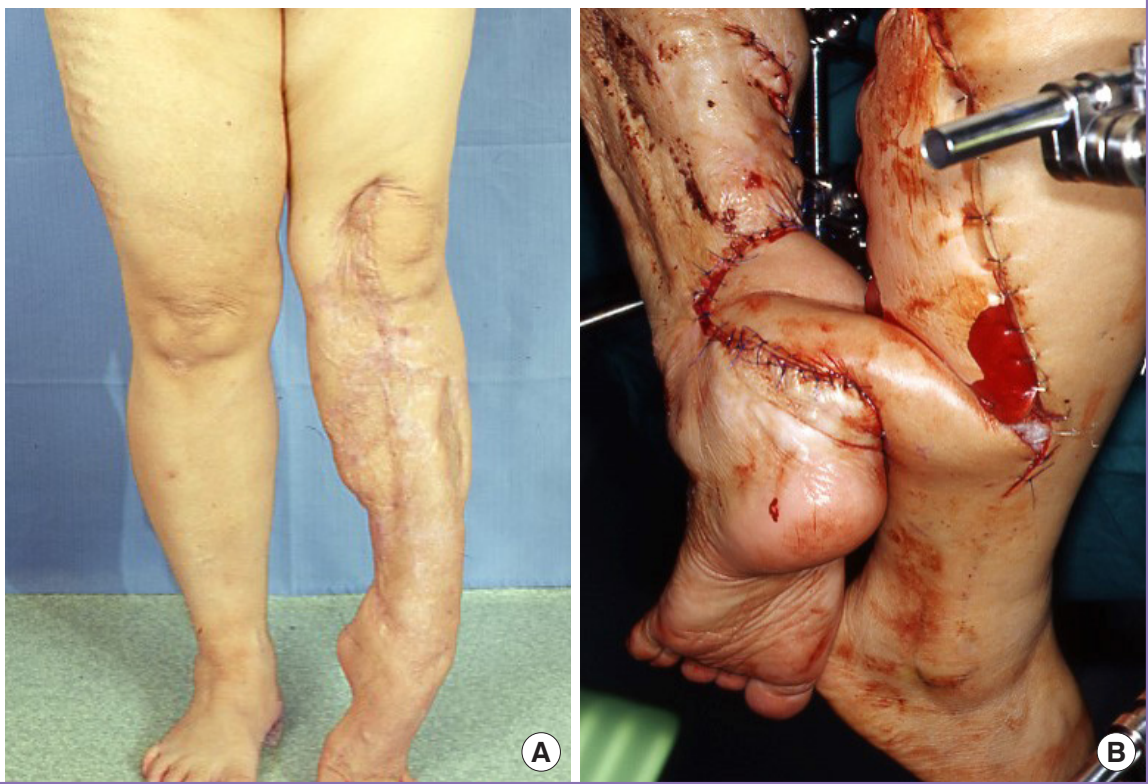


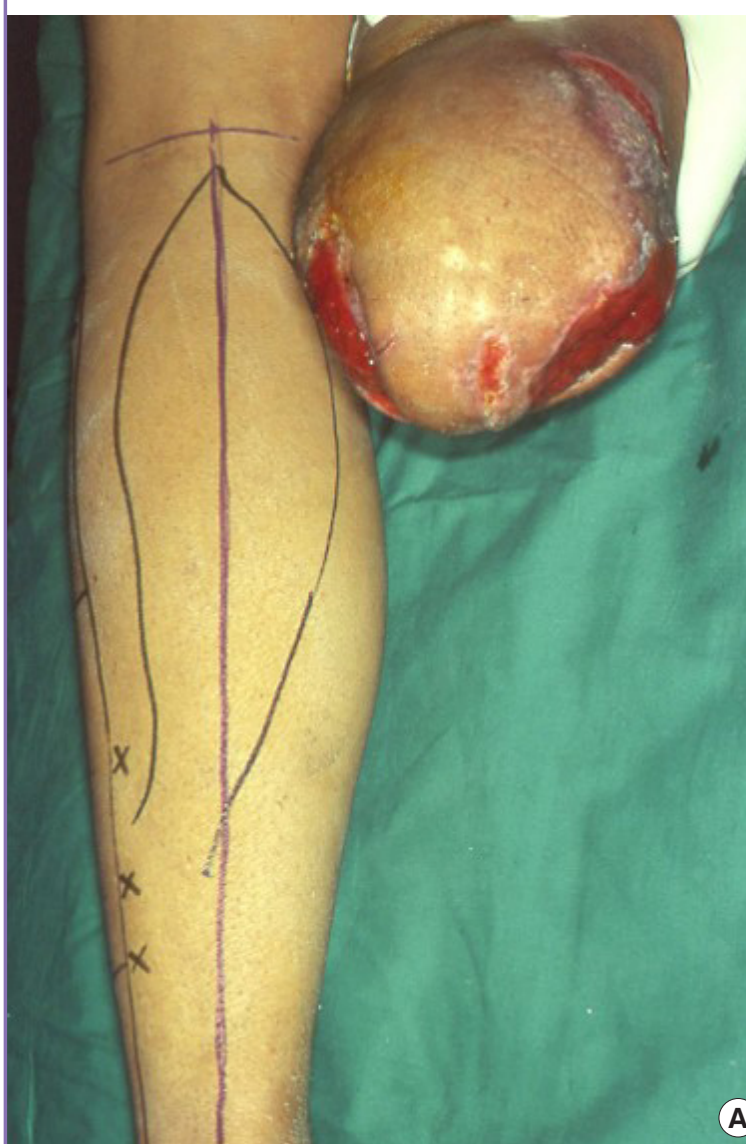

This 30-year-old man sustained a severe crush injury to the right leg, which was not salvageable. (A) A below-knee amputation was performed and the stump was left partially open due to skin deficiency. Markings on the left calf show the flap design. (B) The aim of the external fixator framework design was to maximise flap inset and support of the lower extremities.

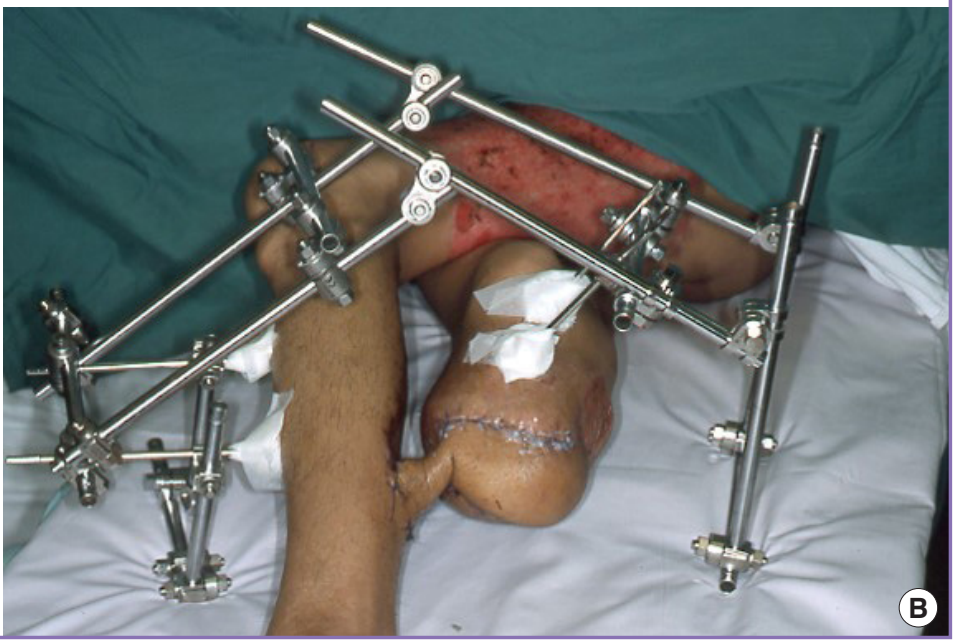

abducted with external fixators to allow complete inset of the flap (Fig. 2B). The flap was divided at 3 weeks after the initial inset with complete survival. With the preservation of amputation stump length and robust skin and soft tissue coverage, a stable prosthesis could be fitted.

\section{Case 3}

A 20-year-old man sustained bilateral tibia-fibula fractures in a motorcycle accident and was treated with intramedullary nailing. The right leg was complicated by osteomyelitis owing to soft tissue loss and vascular injuries. The right intramedullary nail had to be extracted and his leg stabilized with an external fixator. Repeated debridement was performed to arrest the infection, resulting in a 5-cm tibial bone gap. Angiography showed that the posterior tibial artery was the sole vessel supplying the leg. Most of the degloved areas were subsequently skin-grafted, leaving a critical soft tissue defect overlying the bone measuring $6 \times 10 \mathrm{~cm}$. Owing to a paucity of vessels, the decision was made to use an extended cross-leg flap design like that in case 2 (Fig. 3). However, leg immobilization posed a challenge because the existing left tibia intramedullary nail precluded the application of external fixators. A modification employing pins over the fe-
Fig. 3. A severely mangled right lower $\operatorname{limb}$

This 20-year-old man had a single-vessel leg with the posterior tibial artery supplying the foot. After raising the distally based sural artery flap, the sural nerve was included throughout the flap axis (black arrows).

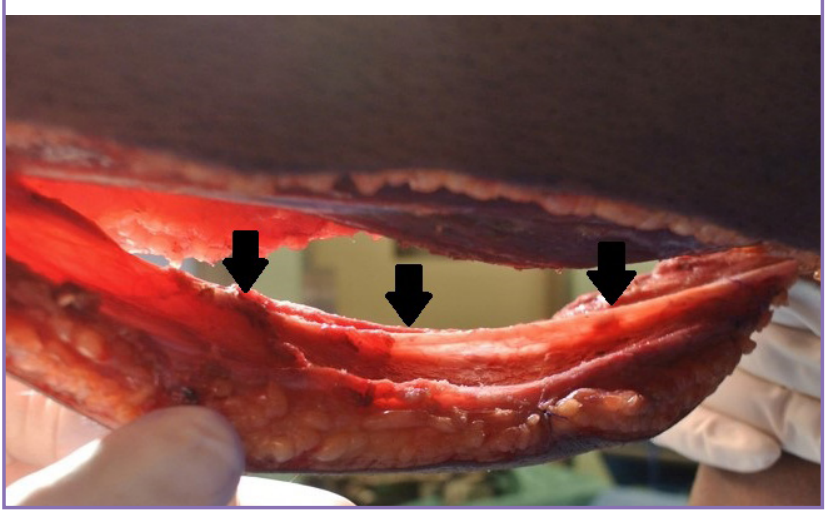

murs, left calcaneum, and first metatarsal bone was necessary to secure the lower extremities in an optimal position for cross-leg transfer of the flap. Flap training was carried out in a similar fashion, and the division was completed after 2 weeks. His wounds had all healed by 1 month after the final flap inset. 


\section{DISCUSSION}

The distally based sural artery flap is a neurovenocutaneous flap that can be reliably extended to the popliteal crease with adequate flap delay [12]. The extended design is particularly important in a cross-leg situation to obtain sufficient reach. To improve the vascularity of these extended flaps, the entire sural neural network and the short saphenous vein are included in the flap. Flap congestion is minimized with two manoeuvres: keeping the flap broad-based, which improves orthograde venous drainage, and intermittent phlebotomy. Blood-letting is accomplished through the cut end of the short saphenous vein every 1 to 2 hours in the first 48 hours to ensure that this axial venous system does not thrombose. By so doing, the venous system is decompressed, as it is connected through oscillating avalvular veins to the vasa nervorum of the sural nerve, which ultimately drains into the deep peroneal venous system [11]. As the oscillating veins hypertrophy and multiply 24 to 48 hours after surgery, venous circulation improves and the cut short saphenous vein spontaneously stops draining. Previous experience has shown that in failed sural artery flaps, the entire short saphenous venous system is clotted with retrograde extension of the thrombus into the deep system.

Routinely, flap delay is performed for these extended flaps. Techniques of flap delay vary, and our preferred method is to raise it as a bipedicled flap and perform tip division gradually. In a cross-leg flap, the tip needs to pick up new blood supply for a successful "waltz-over." Therefore, delay is not rushed, as an ischaemic tip is unable to neovascularize. The same procedure is repeated over the flap's base during waltzing. In our three cases, all extended flaps survived, and their use was maximized with no loss of the bridging portion.

For the successful transfer of cross-leg flaps, the legs are held together securely to prevent shearing and accidental avulsion of the flap. There is a consensus that external fixators are necessary for this purpose as they ensure rigid coupling of the lower extremities. The drawbacks of external fixators include pin site infection and scarring. However, these problems can be reduced by meticulous dressing and wound care. Ideally, a cross-leg external fixation should have a square design with both tibias pinned in parallel. This position is well tolerated and does not restrict knee and hip mobility. However, in the case of the distally based sural artery flap, crossing of the legs is inevitable, as the flap emanates from the lateral aspect of the donor leg (Fig. 4A). For defects around the knee, as in case 2, the extent of leg crossing is more pronounced during the second stage to increase the reach (Fig. 4B). Awkward positioning can cause discomfort, pressure injuries, and difficulty with hygiene. Fine adjustment of the external fixator framework and routine checking are necessary to ensure that gaps are maintained between bony promi-

\section{Fig. 4. Designs of the external fixator framework}

The following designs were used. (A) The basic framework that allowed crossing of the legs for better reach and inset of the flap. (B) Modified design for more extreme leg crossing, allowing the flap to reach defects around the knee. (C) In this design, to circumvent the intramedullary nail in the tibia, the external fixation pins were instead placed proximally in the femur, and distally in the calcaneum and the first metatarsal bone.

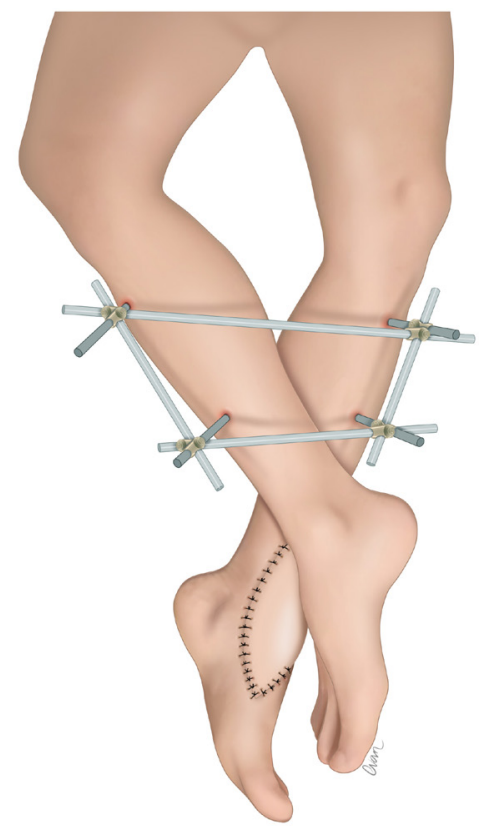

(A)

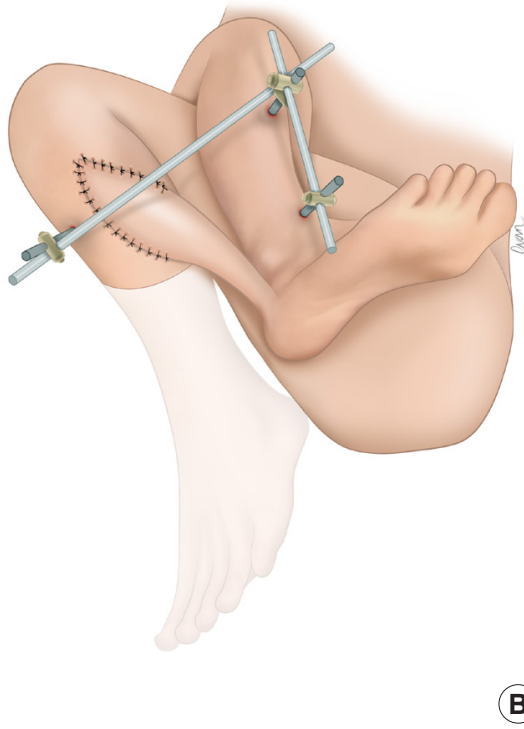

B

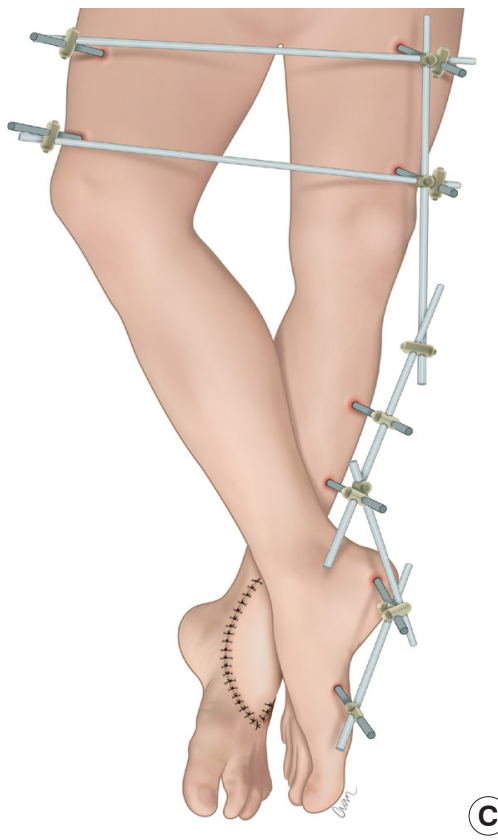


nences.

In the patient in case 3, a tibial intramedullary nail was present in the donor leg. External fixation pins were therefore placed proximally in the femur and distally in the calcaneum (using a monocortical half-Schanz screw) and the first metatarsal bone to avoid the tibia (Fig. 4C). An alternative construct could be one in which a pin is placed through the posterior aspect of the proximal tibia, thereby avoiding the femoral pins. However, this placement would risk infection owing to potential communication of the pin tract with the intramedullary nail.

During prolonged immobilization, the heel is prone to pressure injuries, and we routinely fashion a box frame to elevate the feet (cases 1 and 2). The frame is placed on a firm base (e.g., a sheet of cardboard) to prevent it from sinking into the mattress, and a rolled towel is used to support the knee to prevent hyperextension. In the patient in case 3 , a box frame would have added to his already heavy construct, so we suspended his legs from a Balken frame instead. In this situation, pillow support of his calf was imperative, as his muscles began to sag with gravity and pull away from his tibia. Despite these measures, he developed a grade 2 pressure injury on the heel of the recipient leg. It healed with conservative measures after flap division.

Other cross-leg flaps include the antegrade flow sural artery flap, distally based soleus flap, and free flap $[2,13,14]$. For case 2, the cross-leg antegrade flow sural artery flap incorporating the short saphenous vein was advantageous, as the flap would not have venous congestion, thus obviating the need for delay. The cross-leg soleus flap is inherently disadvantaged, since as with all muscle flaps, their high metabolic demand prevents neovascular takeover. In contrast, fasciocutaneous flaps are less fastidious and pick up new blood supply readily from the subdermal plexus at the recipient site. In the cross-leg free flap, the opposite leg provides the recipient vessels for a single or double (sequential) cross-leg flap(s). In the latter, a tubed radial forearm flap serves as a bridging flap on which a second flap, such as latissimus dorsi flap, is vascularized [2]. This configuration affords a long pedicle length for greater comfort. However, as with all free flap reconstructions, concern remains regarding donor site morbidity, the risk of anastomotic failure, and the duration of surgery.

\section{NOTES}

\section{Conflict of interest}

No potential conflict of interest relevant to this article was reported.

\section{Ethical approval}

The study was approved by the Institutional Review Board of Sin- gapore General Hospital (CIRB No. 2019/2227) and performed in accordance with the principles of the Declaration of Helsinki. Written informed consents were obtained.

\section{Patient consent}

The patients provided written informed consent for the publication and the use of their images.

\section{Author contribution}

Conceptualization of study, review and approval of manuscript, and study supervision: Tan BK. Literature review, clinical study, and drafting and editing of manuscript: Liang W.

\section{ORCID}

Weihao Liang https://orcid.org/0000-0002-1088-583X

Bien Keem Tan https://orcid.org/0000-0002-7347-8713

\section{REFERENCES}

1. Devansh S. Prefabricated recipient vascular pedicle for free composite-tissue transfer in the chronic stage of severe leg trauma. Plast Reconstr Surg 1995;96:392-9.

2. Chen H, El-Gammal TA, Wei F, et al. Cross-leg free flaps for difficult cases of leg defects: indications, pitfalls, and longterm results. J Trauma 1997;43:486-91.

3. Quarmby CJ, Skoll PJ. The distally based, cross-leg, sural artery island flap. Plast Reconstr Surg 2001;108:798-9.

4. Atiyeh BS, Al-Amm CA, El-Musa KA, et al. Distally based sural fasciocutaneous cross-leg flap: a new application of an old procedure. Plast Reconstr Surg 2003;111:1470-4.

5. Masquelet AC, Romana MC, Wolf G. Skin island flaps supplied by the vascular axis of the sensitive superficial nerves: anatomic study and clinical experience in the leg. Plast Reconstr Surg 1992;89:1115-21.

6. Almeida MF, da Costa PR, Okawa RY. Reverse-flow island sural flap. Plast Reconstr Surg 2002;109:583-91.

7. Al-Qattan MM. A modified technique for harvesting the reverse sural artery flap from the upper part of the leg: inclusion of a gastrocnemius muscle "cuff" around the sural pedicle. Ann Plast Surg 2001;47:269-74.

8. Tosun Z, Ozkan A, Karacor Z, et al. Delaying the reverse sural flap provides predictable results for complicated wounds in diabetic foot. Ann Plast Surg 2005;55:169-73.

9. Tan BK, Wong CH. An anomalous septocutaneous perforator to the skin paddle of the fibula osteocutaneous flap originating from the posterior tibial artery. J Plast Reconstr Aesthet Surg 2009;62:690-2.

10. Mok WL, Por YC, Tan BK. Distally based sural artery adi- 
pofascial flap based on a single sural nerve branch: anatomy and clinical applications. Arch Plast Surg 2014;41:709-15.

11. Wong CH, Tan BK. Intermittent short saphenous vein phlebotomy: an effective technique of relieving venous congestion in the distally based sural artery flap. Ann Plast Surg 2007;58:303-7.

12. Mojallal A, Wong C, Shipkov C, et al. Vascular supply of the distally based superficial sural artery flap: surgical safe zones based on component analysis using three-dimensional computed tomographic angiography. Plast Reconstr Surg 2010; 126:1240-52.

13. Fayman MS, Orak F, Hugo B, et al. The distally based split soleus muscle flap. Br J Plast Surg 1987;40:20-6.

14. Pu LL. The reversed medial hemisoleus muscle flap and its role in reconstruction of an open tibial wound in the lower third of the leg. Ann Plast Surg 2006;56:59-63. 